\title{
Good video game players look better: exploring the relationship between game skills, sexual dimorphism, and facial attractiveness
}

\author{
Xiangqian $\mathrm{Li}^{1,2} \cdot$ Xue Lei $^{3} \cdot$ Ruxue $\mathrm{Xie}^{4} \cdot$ Chen $\mathrm{Xu}^{2} \cdot$ Shitao Chen ${ }^{5} \cdot$ Chengyang Han ${ }^{5}$. Shichang Deng ${ }^{6}$
}

Accepted: 5 July 2022

(c) The Author(s), under exclusive licence to Springer Science+Business Media, LLC, part of Springer Nature 2022

\begin{abstract}
Few studies have been done on the effects of video games on social perception, especially on the faces of players. The present study investigated how people's gaming skill influences their perceived facial attractiveness, and also how sexual dimorphism features (masculine and feminine) interplayed with displayed gaming skill. We asked players $(N=147)$ and non-players $(N=167)$ to evaluate the attractiveness of masculinized and feminized facial images, along with perception of gaming skills (high gaming skill or low gaming skill). The results indicated that game players perceived facial images accompanied by higher gaming skill information were more attractive than facial images accompanied by lower gaming skill information. However, for participants without gaming experience (i.e., non-players), gaming skill information did not influence their evaluation of attractiveness. We believe players might consider higher gaming skills as social knowledge which can positively influence people's perception of their attractiveness; on the other hand, non-players did not perceive gaming skills as important social knowledge, hence attractiveness ratings were unaffected. We did not find any interactions between sexual dimorphism features and gaming skill information. To our surprise, only non-players exhibited classic sexual dimorphism effects in facial evaluations, whereas for players, the sexual dimorphism effect disappeared completely. We speculate that players rely more on social knowledge and less on configuration cues during facial evaluation, hence the effects of sexual dimorphism were obscured.
\end{abstract}

Keywords Game skills $\cdot$ Sexual dimorphism $\cdot$ Facial attractiveness $\cdot$ Social knowledge

Video game playing has become a common activity in today's society. In 2020, the total global sales of digital

Xiangqian Li and Xue Lei share first authorship.

Shichang Deng

dengsc@ suibe.edu.cn

1 School of Psychology, Shanghai University of Sport, Shanghai, China

2 Laboratory of Social Psychology and Behavioral Science, Fudan University, Shanghai, China

3 School of Business Administration, Zhejiang University of Finance and Economics, Hangzhou, China

4 School of Arts and Sciences, Rutgers University, New Jersey, USA

5 Department of Psychology, Hangzhou Normal University, Hangzhou, China

6 School of Management, Shanghai University of International Business and Economics, Room 216, Lequn Building, No.1900 Wenxiang Road, Shanghai 201620, China games exceed $\$ 127$ billion $^{1}$, and a recent study predicted that the total value of the market should reach $\$ 300$ billion by $2027^{2}$. Therefore, its potential consequences on players' social perceptions are worth considering. In fact, over the past two decades, psychology studies on video game experience have focused primarily on aspects of players' visual perception, attention, and cognitive control (e.g., Boot et al., 2008; Bediou et al., 2018; Chopin et al., 2019; Dobrowolski et al., 2015; Green \& Bavelier, 2003, 2006; Li et al., 2020; Nuyens et al., 2019; Unsworth et al., 2015). To our knowledge, few studies has yet investigated the relationship between social perception and gaming experience.

\footnotetext{
1 See the SuperData's “2020 Year in Review” report, available at https://www.gamesindustry.biz/articles/2021-01-06-digital-gamesspending-reached-USD127-billion-in-2020, accessed on 26th June 2022.

2 See the report of "Gaming Market - Growth, Trends, Covid-19 Impact, and Forecasts (2022-2027)", available at https://www.mordo rintelligence.com/industry-reports/global-games-market, accessed on 26th June 2022.
} 
In this study, we sought to learn whether personal gaming experience or gaming-related information affects people's judgment during social interactions. Particularly, would people (players and/or non-players) think high-skilled video game players are more good-looking or less good-looking? A large number of studies have shown that the evaluation of facial attractiveness plays an important role in social interactions. It not only influences mating preference and social assessments of age and health (Sutherland et al., 2016; Vernon et al., 2014), but also has strong influences on social interactions (Olivola et al., 2014; Todorov et al., 2015). Hence, to provide reference for the study of electronic games and social cognition in the future, we wished to explore how game-related factors influence participants' evaluation of game players' facial attractiveness in this research.

\section{Game skills as a social knowledge affects players' facial attractiveness}

For video game players, maintaining a certain level of gaming skills is a prerequisite for them to derive enjoyment from videogames. Many research reviews have also listed game skills as an important variable in the study of video games and psychology (e.g., Nuyens et al., 2019; Chopin et al., 2019). Therefore, we included game skills as an important variable in this study.

In recent years, researchers have demonstrated that individuals' personality characteristics may affect their attractiveness. Individuals with positive personality characteristics tend to receive higher attractiveness ratings compared with individuals with negative social knowledge (e.g., Han et al., 2020; Little et al., 2006; Wang et al., 2020; Zebrowitz $\&$ Franklin, 2014). For example, in Wang et al.'s (2020) research, facial images appeared with a statement describing individual characteristics in terms of competence or warmth: facial images that appeared with positive statements tended to receive higher attractiveness ratings. In these studies, the information that reveals personality characteristics is referred to as social knowledge.

We propose that gaming skills could be considered a special kind of social knowledge because knowing people's gaming skill may give also us a glimpse into other personal characteristics (Karakus et al., 2008). For example, we might believe that players who are good at competitive games have higher competence (Kowert \& Oldmeadow, 2013). Hence, if participants can perceive a player's competence level from their gaming skills, they should give players with higher gaming skills higher facial attractiveness ratings.

Furthermore, to perceive players' individual characteristics from their gaming skill, one must understand the context of the game. For example, if we did not know that a game is highly competitive, we might not perceive a top player of that game as more competitive (Kowert \& Oldmeadow, 2013). Therefore, we also hypothesize that the effect of gaming skill information on facial evaluation should be categorized by participants' gaming experience. For nonplayers, the effects of gaming skill information should not be as strong. Based on the above reasoning, we propose the following hypothesis:

$\mathrm{H} 1$ : We predicted an interplay between gaming skill information (high/low) and participants' gaming experience (player/non-player): for players, high gaming skill information would increase their facial attractiveness rating. But for non-players, the gaming skill information should have less impact on facial evaluations.

\section{Sexual dimorphism, game skills, and players' facial attractiveness}

Sexual dimorphism is another important factor affecting the evaluation of facial attractiveness. Studies have consistently shown that female faces with more feminine features are perceived as more attractive than female faces with more masculine features (Rhodes, 2006; Scott et al., 2008). Analogously, male faces with more masculine features are perceived as more attractive (DeBruine et al., 2010; Perrett et al., 1998; Han et al., 2021; but also see Burriss et al., 2014); however, the masculinity-attractiveness association may shift by various factors, such as external environment and hormone levels (see Stephen \& Luoto, 2021 for a review).

Recent studies further proposed that sexual dimorphism could interplay with the dimension of social knowledge and the gender of the faces (Wang et al., 2020). In particular, Wang et al. (2020) reported that when evaluating male faces masculine features combined with competence information further improved the attractiveness rating (comparing to faces paired with noncompetence information). However, contrary to males, competence information reduced the attractiveness of the female faces with feminine features. In other words, competence information amplified the sexual dimorphism effect for male faces but reduce the dimorphism effect for female faces.

For the present study, we reasoned that as video games are mostly competitive, participants should consider high gaming skill information as one type of competence information. However, low gaming skill information should less likely be considered as competence information. Therefore, we predict that compared to low gaming skill information, when facial images are paired with high gaming skill information, participants should demonstrate a larger sexual dimorphism perception effect in male faces, but a smaller sexual dimorphism 
Fig. 1 Conceptual model of this study. H1: For players, higher gaming skill information increase facial attractiveness ratings. $\mathrm{H} 2$, facial gender further regulates the relationship between gaming skill information and the attractiveness rating (more) Game experience

(players vs. non-players )

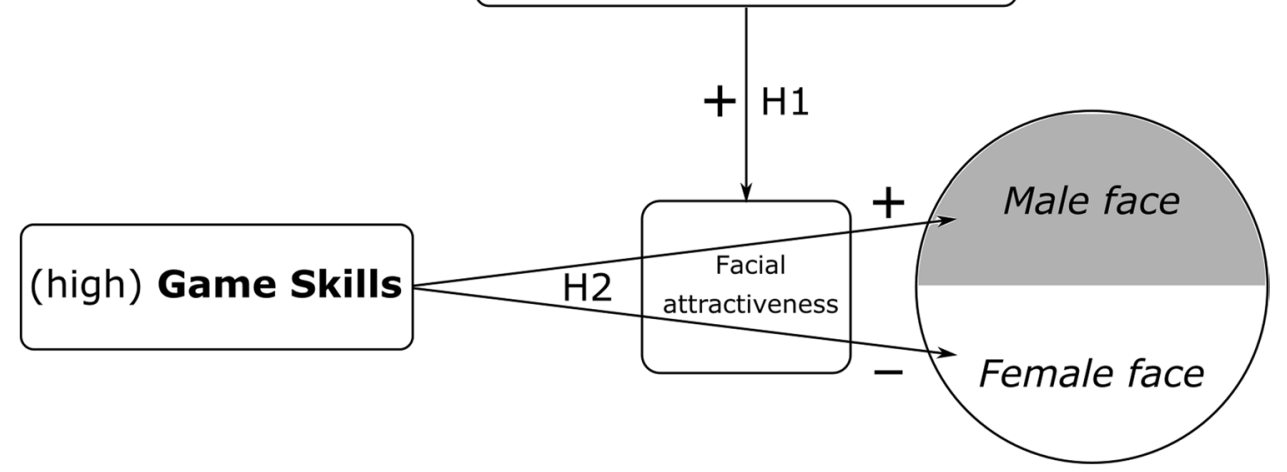

perception effect in female faces. Based on the above reasoning, we propose the following hypothesis:

$\mathrm{H} 2$ : Compared to low gaming skill information, high gaming skill information should increase the attractiveness rating of masculine male faces but reduce the attractiveness rating of feminine female faces, thus causing an interplay between gaming skill information and sexual dimorphism perception effects.

Our hypotheses are summed up in Fig. 1.

\section{The target game of the study}

In order to control participants' gaming experience and to show game skill information, we selected League of Legends (LOL) as our target game, for two reasons. Firstly, LOL has a ranking system that can objectively reflect players' gaming skills. In short, the ranking system divided players into nine different divisions or 27 levels based on players' gaming skills. Secondly, it was relatively easier to find participants with LOL game experiences, as LOL is currently one of the most popular action video games in the world. According to Riot (one of the largest American video game developers and e-sports tournament organizers), as of July 2021, LOL has nearly 117 million active players around the world (https://leaguefeed.net/did-you-know-total-league-of-legen ds-player-count-updated).

\section{Method}

\section{Research ethics and data disclosure}

The approval of ethical standards for the present study was given by the Ethics Committee of authors' institution. All participants provided informed consent by checking a box to confirm they had fully understood the implications of participation and their right to withdraw at any point. The data that support the results of the present study are openly available in Open Science Framework at: https://osf.io/b6ukf/? view_only=5155d45b0a1f482a9ab34f99e16edda0.

\section{Design and participants}

The study employed a four-way mixed design. Two withinsubjects factors were Gender of the Face (male / female) and Sexualized Characteristics (masculinized / feminized). Two between-subjects factors were Gaming Skill Information (high / low) and Gaming Experience (game player / non-player). $G^{*}$ Power 3.1 was used to calculate the required sample size (Faul et al., 2007). The parameters were set as follows: the effect size $F$ was 0.25 (medium), alpha was 0.05 (default), 1-beta was 0.80 (default), the number of groups was 4 , the number of times of measurements was 4 , and the correlation between repeated measures was 0.5 . The sample size was calculated to be 116 individuals or 29 participants per participant group.

Participants were recruited mainly by advertising in an online subject pool (a social media group) of authors' institution, while a small number of participants were invited by word of mouth from among some students at authors' institution. Eventually, 314 people participated in the present study; see Table 1 for group demographics. Our criteria for classifying LOL players and non-players was straightforward: Participants who had played LOL in the last six months were classified as players, and non-players had never played LOL before. On average, our players had played LOL for 4.27 years and played $6.06 \mathrm{~h}$ per week.

\section{Apparatus and stimuli}

The online experiment was performed using the Psytoolkit online platform (Stoet, 2010, 2017). For the gaming skill 
Table 1 Group demographics

\begin{tabular}{|c|c|c|c|c|}
\hline \multirow[t]{2}{*}{$\begin{array}{l}\text { Participant } \\
\text { group }\end{array}$} & \multicolumn{2}{|c|}{$\begin{array}{l}\text { Gaming skill information } \\
\text { Condition 1: High level }\end{array}$} & \multicolumn{2}{|c|}{$\begin{array}{l}\text { Gaming skill information } \\
\text { Condition 2: Low level }\end{array}$} \\
\hline & Player & Non-player & Player & Non-player \\
\hline$N$ & 75 & 84 & 72 & 83 \\
\hline Age: $M(S D)$ & $21.31(1.42)$ & $21.50(1.66)$ & $21.47(1.37)$ & $20.91(2.17)$ \\
\hline Female: $N(\%)$ & $30(40)$ & $48(57.14)$ & $29(40.27)$ & $50(60.24)$ \\
\hline Male: $N(\%)$ & $45(60)$ & 35 (41.66) & $43(59.72)$ & $33(39.75)$ \\
\hline $\begin{array}{l}\text { Play Years: } M \\
\quad(S D)\end{array}$ & $4.06(2.98)$ & - & $4.50(3.13)$ & - \\
\hline $\begin{array}{l}\text { Play Hours: } \\
M(S D)\end{array}$ & $4.17(6.32)$ & - & $3.47(8.45)$ & - \\
\hline
\end{tabular}

Psytoolkit online platform would randomly assign participants into experiment groups; Play Hours reflects how many hours the player plays LOL per week

information groups, badges and explanatory note (see Fig. 2a) was applied to indicate the game's ranking divisions and levels. We selected top ten rank levels as high gaming skills (from Challenger to Platinum III) and the bottom ten levels as low gaming skills (from Iron IV to Silver III).

For the facial images, we adopted a total of 40 Chinese facial images from Han et al. (2021)'s study, which contained 10 pairs being the female face images and 10 pairs being the male face images. In other words, each "person's" facial image had two versions, the masculine version, and the feminine version, forming a pair of facial images (see Fig. 2b). Han et al. (2021) applied prototype-based image transformation methods (e.g., Bird et al., 2016; Welling et al., 2008) to manipulate the sexual dimorphism features. The effects of the sexual dimorphism manipulation were reliable, as Han et al. (2021) found that in an attractive judgment task, young adults (i.e., college students) showed a preference for masculine male faces and feminine female faces. However, it should be noted that a preference for masculine male faces is not universal (see Stephen \& Luoto, 2021).

\section{Procedure}

Participants first read a short description of the experiment. Then they were asked to click a box to confirm that they had agreed to participate in the experiment and informed that they had the right to withdraw at any point. After that, participants needed to read on-screen instructions and then finish the facial attractiveness rating task. They were asked to rate the attractiveness of some LOL players' faces and were informed that each player's face would appear twice with slight variations (i.e., the masculinized and feminized versions, but participants did not know that the difference was due to sexual dimorphism). In the attractiveness rating task, male and female faces would appear on the screen along with the gaming skill information. The Psytoolkit online platform would randomly assign participants into the high gaming skill group or low gaming skill group. The difference was that in the high gaming skill group, facial images appeared with badges and explanatory notes indicating one of the top rank levels; while in the low gaming skill group, facial images appeared with badges and explanatory (a)

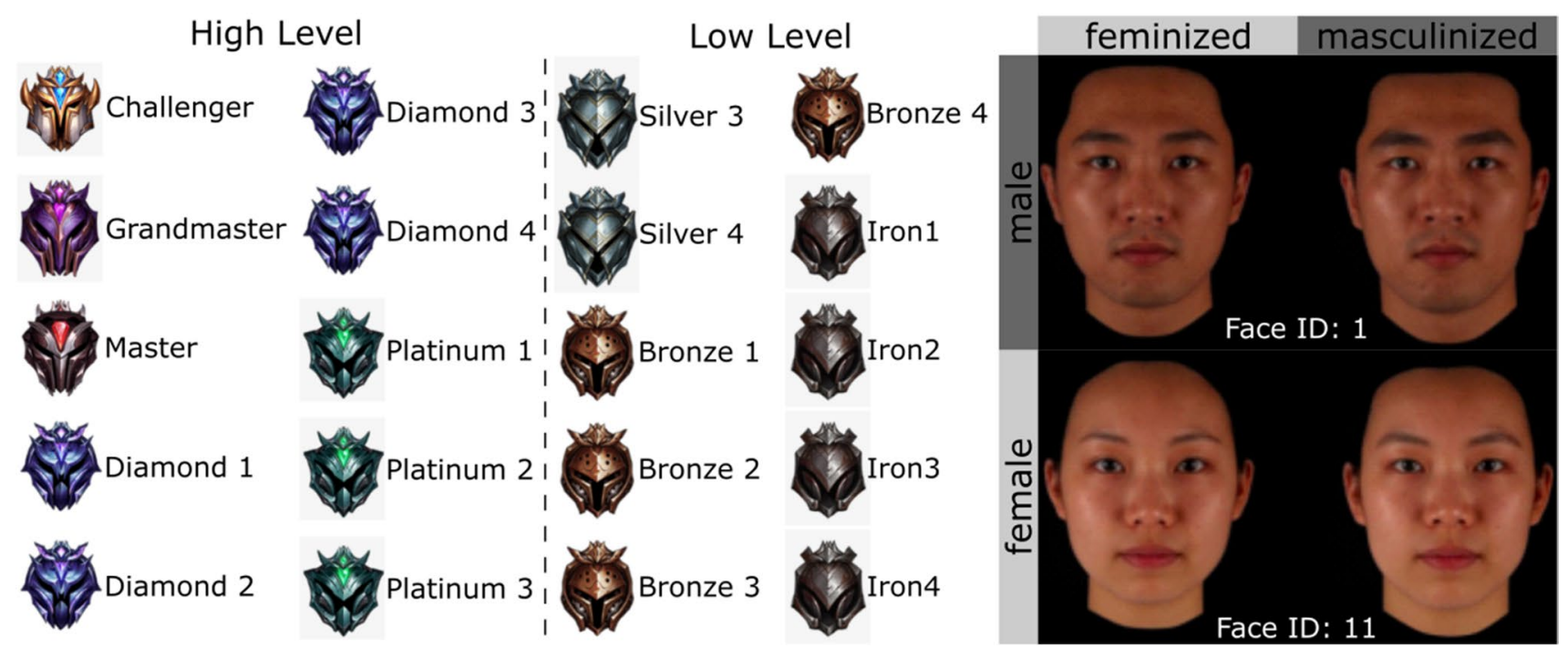

Fig. 2 Stimuli in the present study. a Gaming skill information: Rank levels are demonstrated by badges and explanatory notes. Top ten levels (left side; from Challenger to Platinum III) indicate high gaming skill, and bottom ten levels (right side; from Iron IV to Silver III) indicate low gaming skill. b Examples of facial images. Each Face ID contend a pair of faces, the feminized version (left) and the masculinized version (right) 
Fig. 3 Single experiment flow chart based on the experiment procedure

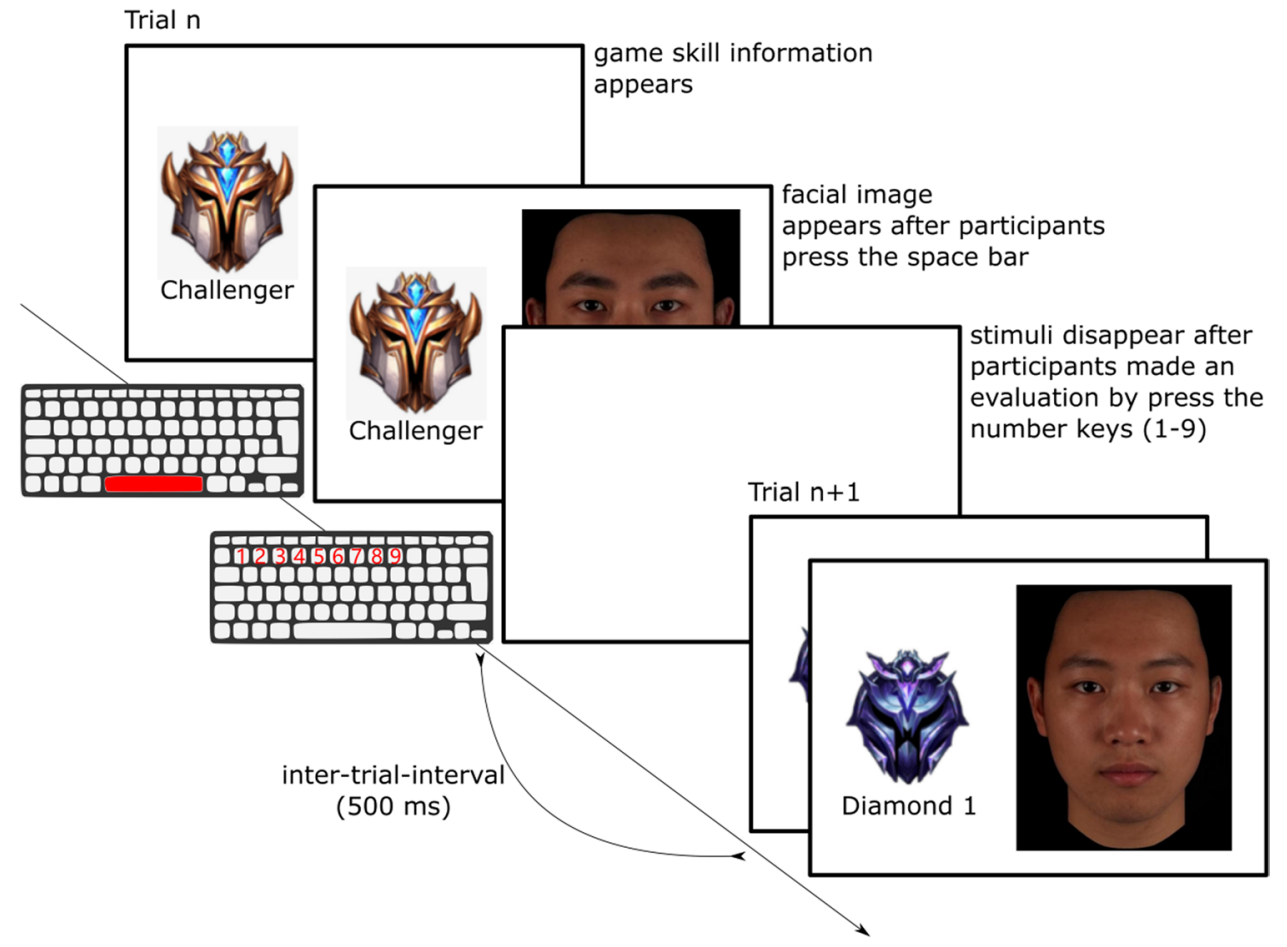

notes indicating one of the bottom ranks. Notice that each version of a "player's face" (masculinized or feminized) was assigned with the same rank.

In each trial, the gaming skill information appeared on the screen first; participants were asked to press the space bar after they read the gaming skill information. After that, the facial images appeared on the screen, and participants were then asked to rate how attractive they felt that the face was using the number keys at the top of the keyboard ( 1 point=very unattractive, 9 points = very attractive). There was no time limit for participants to respond. After participants entered each response, stimuli would disappear and the next trial would start automatically after a 500 ms inter-trial interval (Fig. 3). The task included four blocks: male masculinized block, female masculinized block, male feminized block, and female feminized block, each block containing 10 face images. The block order was randomized between participants.

\section{Results}

Ratings on the attractiveness-judgment task was analyzed using linear-mixed models in R Version 3.6.0 (Core Team, 2019), and lmerTest version 3.1.0 (Kuznetsova et al., 2017). We tested models with a full factorial design (fixed effects for Face Gender, Sexualized Characteristics, Gaming Skill and Play Group, and their interactions). In addition to the fixed effect, Subject ID and Face ID (we give each pair of facial images a unique Face ID) were treated as random-effects factors. We identified the most parsimonious model that converged which had a by-subject random effect for Face Gender (slopes) and also gave each pair of face images (i.e., Face ID) a different intercept for mean attractiveness rating.

In terms of significance, we used the ANOVA function in R's lmerTest (Kuznetsova et al., 2017) to obtain the $p$-values and $F$ statistics for each fixed effect. The ANOVA function computed $p$-values based on the Satterthwaite approximations method, which gives the most optimal Type 1 error rate across different sample sizes (Luke, 2017). Results of all fixed effects are summarized in Table 2 and illustrated in Fig. 4. For reference, the results of ANOVA with only fixed effects (no random effect) can be found in the Appendix Table 3.

We found that the main effect of gaming skill was significant: face images with higher rank information $(M=4.74)$ received higher attractiveness ratings than face images with lower rank information $(M=4.16)$. Further pairwise comparisons with Holm (1979) correction suggested that the effect of gaming skill was significant in both male facial images (high rank vs. low rank $=4.58$ vs. $3.97, p<.001$ ) and female facial images (high rank vs. low rank $=4.89$ vs. 4.35 , $p<.001)$. In the following, post hoc pairwise comparisons were always adjusted for multiple comparisons after Holm (1979). Other main effects were not significant.

The two-way interaction between Gaming Skill and Player Group was significant. Pairwise comparisons revealed that gaming skill information only had a significant impact in the game-player group: game-players tended to give higher attractiveness rating for the face image with high rank information than face image with low rank information (4.89 vs. $4.05, p<.001)$, but in the non-player group, the difference of attractiveness ratings between high rank face image and low rank face image was not significant (4.58 vs. 4.27, $p=.087$ ). 
Table 2 Results of the fixed effects from the most parsimonious model:Attractiveness $\sim$ Face Gender $\times$ Sexualized Characteristics $\times$ Gaming Skill $\times$ Play Group $+(0+$ Face Gender I subject id $)+(1$ | face id)

\begin{tabular}{lllll}
\hline Factor & $F$ & $d f$ & $p$ & $\eta_{p}^{2}$ \\
\hline Face Gender & 2.41 & $(1,11,906)$ & 0.132 & 0.011 \\
Sexualized Characteristics & 2.21 & $(1,11,906)$ & 0.137 & $<0.001$ \\
Gaming Skill & $\mathbf{1 9 . 1 9}$ & $(\mathbf{1 , 3 1 0 )}$ & $<\mathbf{0 . 0 0 1}$ & $\mathbf{0 . 0 5 8}$ \\
Player Group & 0.09 & $(1,310)$ & 0.761 & $<0.001$ \\
FG $\times$ SC & $\mathbf{3 0 . 2 6}$ & $(\mathbf{1}, \mathbf{1 1 , 9 0 6 )}$ & $<\mathbf{0 . 0 0 1}$ & $\mathbf{0 . 0 0 3}$ \\
FG $\times$ GS & 0.40 & $(1,310)$ & 0.526 & 0.001 \\
SC $\times$ GS & 2.17 & $(1,11,906)$ & 0.141 & $<0.001$ \\
FG $\times$ PG & 6.70 & $(1,11,906)$ & 0.010 & 0.021 \\
SC $\times$ PG & 3.74 & $(1,11,906)$ & 0.053 & $<0.001$ \\
GS $\times$ PG & $\mathbf{4 . 1 5}$ & $(\mathbf{1}, \mathbf{3 1 0})$ & $\mathbf{0 . 0 4 2}$ & $\mathbf{0 . 0 1 3}$ \\
FG $\times$ SC $\times$ GS & 0.27 & $(1,11,906)$ & 0.598 & $<0.001$ \\
FG $\times$ SC $\times$ PG & $\mathbf{5 . 2 5}$ & $(\mathbf{1 , 1 1 , 9 0 6 )}$ & $\mathbf{0 . 0 2 2}$ & $\mathbf{0 . 0 0 2}$ \\
FG $\times$ GS $\times$ PG & 0.61 & $(1,11,906)$ & 0.434 & $<0.001$ \\
SC $\times$ GS $\times$ PG & 1.35 & $(1,11,906)$ & 0.244 & $<0.001$ \\
FG $\times$ SC $\times$ GS $\times$ PG & 1.53 & $(1,11,906)$ & 0.216 & $<0.001$ \\
\hline
\end{tabular}

$\mathrm{FG}=$ Face Gender; $\mathrm{SC}=$ Sexualized Characteristics; GS = Gaming Skill; $\mathrm{PG}=$ Play Group

Bold means the $p$-value is less than 0.05

The two-way interaction between Face Gender and Sexualized Characteristics was significant, and the three-way interaction between Face Gender, Sexualized Characteristics and Play Group was also significant. In order to better understand these interactions, we further analyzed the interaction between Face Gender and Sexualized Characteristics in players and non-players separately. Our results showed that the interaction between Face Gender and Sexualized Characteristics was only significant in the non-player group, $F$ $(1,11,906)=32.22, p<.001$. Pairwise comparisons revealed that non-players tended to give masculine male faces $(M=4.30)$ higher attractiveness rating than feminine male faces $(M=4.07), p<.001$. In contrast, non-players tended to give feminine female faces $(M=4.71)$ higher attractiveness ratings than masculine female faces $(M=4.63), p=.024$. However, the interaction between Face Gender and Sexualized Characteristics was not significant for game-players.

\section{Discussion}

The main purpose of the present study was to investigate whether the knowledge of gaming skills affects facial attractiveness evaluation, and how participants' gaming experience and sexual dimorphism features interplay with the knowledge of gaming skills. Consistent with hypothesis H1, participants tended to give facial images with high gaming-skill information higher attractiveness ratings than facial images with low gaming-skill information. Our results were also consistent with previous studies (Han et al., 2020; Little et al., 2006; Wang et al., 2020; Zebrowitz \& Franklin, 2014), suggesting that positive social knowledge can increase attractiveness rating. Moreover, in the present study, the attractiveness ratings differed significantly between high-gaming-skill faces and low-gaming-skill faces in participants with gaming experience, but the difference was only marginally significant $(p=.087)$ in participants with no gaming experience, suggesting that valence of social knowledge may be influenced by individual experience or value judgment. Game-players might perceive higher gaming skills as more positive than non-players. It is worth mentioning that due to the popularity of LOL, although non-players had not played the target game (i.e., LOL) personally, they might still receive game-related experience, such as watching live streams or watching League of Legends professional games. Hence, non-players might still perceive higher gaming skills as more positive. Indeed, for non-players, faces shown up with high gaming skills still induce them to rate higher on attractiveness than faces shown up with low gaming skills, although the difference was not significant. We suspect that for people who perceive video games as negative social knowledge (e.g., older Chinese generations with no gaming experience), information of higher gaming skills may actually reduce the facial attractiveness rating.

Gaming skill in the present study was indicated in a hierarchical ranking fashion (from the lowest, Iron division, to Diamond division and eventually to the highest, Challenger division). Therefore, some might argue that the gaming skill information might insinuate higher social status, which might also increase facial attractiveness rating (Oh et al., 2020; Dunn \& Searle, 2010; Dunn \& Hill, 2014; Mattan et al., 2017). However, unlike positive social knowledge, which tends to increase the attractiveness ratings in both male and female face images (Han et al., 2020; Little et al., 2006; Wang et al., 2020; Zebrowitz \& Franklin, 2014), a positive status only increases male facial attractiveness rating (Dunn \& Searle, 2010; Dunn \& Hill, 2014). In fact, sometimes higher-status females can be judged negatively (Glick et al., 2005; Heilman et al., 2004; Howlett et al., 2015). Our results showed that high gaming skill information increases attractiveness rating for both male and female facial images. As a result, we suggest that the increment was most likely due to positive social knowledge but not status cues.

In terms of the sexual dimorphism effects, our results did not support H2. There was no interaction between sexual dimorphism effects and social knowledge. More peculiarly, we only observed sexual dimorphism effects among nonplayers: non-players rated masculinized male faces as more attractive than feminized male faces, and rated feminized female faces as more attractive than masculinized female faces, which replicated the results of facial dimorphism effects (DeBruine et al., 2010; Han et al., 2021; Perrett et al., 1998; Rhodes, 2006; Scott et al., 2008). In contrast, the 
Fig. 4 Results of the present study. a The violin plots illustrate the attractiveness rating distributions of the non-players and game-players for low gaming (skill) information and high gaming (skill) information. Overlaid jittered dots represent the average attractiveness rating of each participant. The black horizontal bar and the box around it represents the mean and $95 \% \mathrm{CI}$ of the mean for each condition, respectively. b The violin plots illustrate the attractiveness rating distributions of non-players (top) and game players (bottom) for each face gender and sex characteristic condition

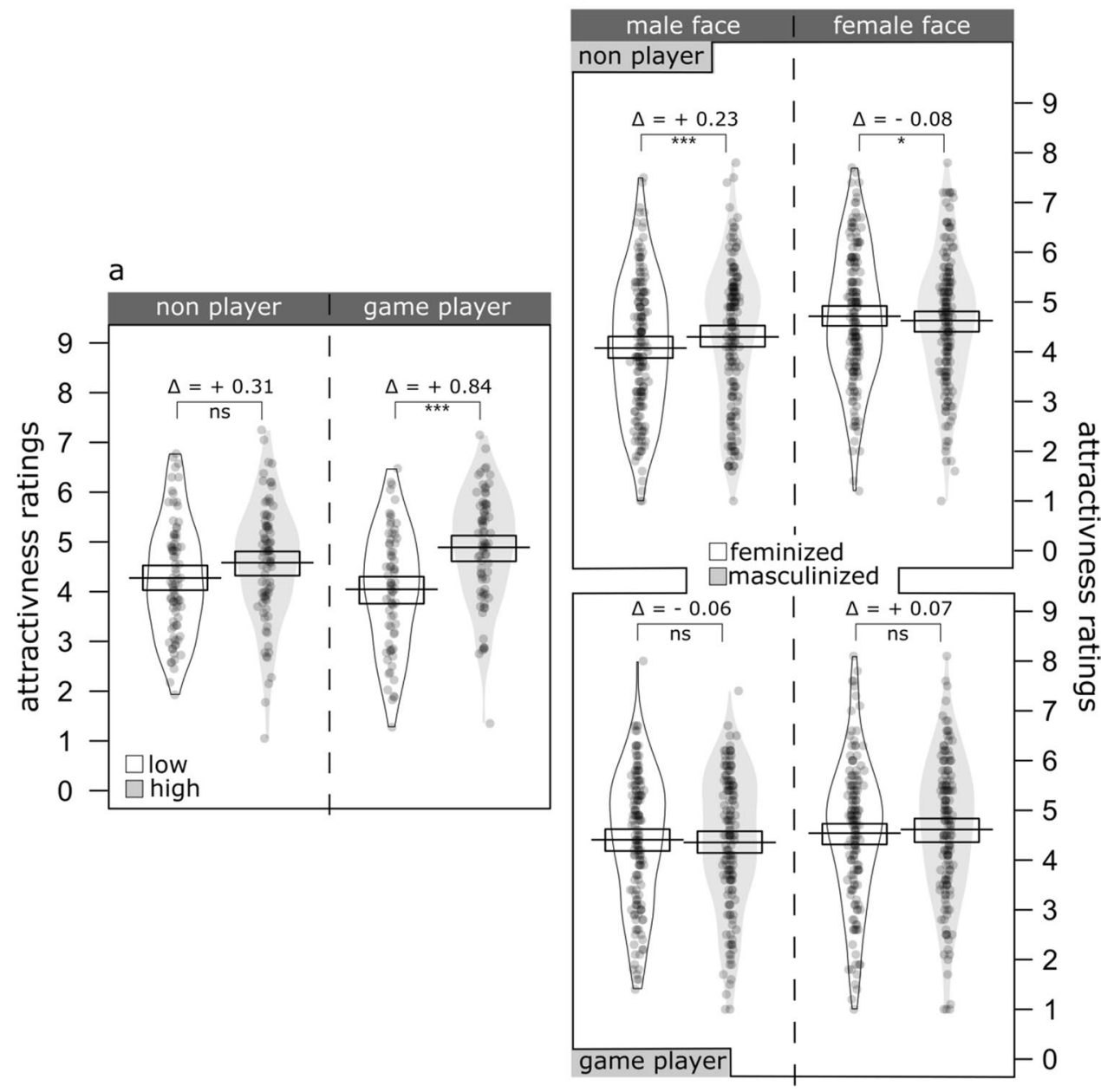

b

One speculation is that, due to their insufficient background in video gaming, non-players might not be able to infer personality characteristics from the given social knowledge (i.e., the game skill information), and so they received more influence from the configuration cues (i.e., the bottom-up route). As a consequence, the effect of gaming-skill information was not significant, but the sexual dimorphism effect was significant among non-players. In contrast, LOL players might consider themselves to belong to the same social group; therefore, when LOL players evaluate other LOL players' facial images, due to the in-group favoritism effect (Mullen et al., 1992; Everett et al., 2015), they rely more on social knowledge (i.e., the top-down route) and less on configuration cues (bottom-up route), hence the effects of sexual dimorphism are obscured, but the effect of gaming-skill information was significant. To confirm this inference, future studies can manipulate the in-group favoritism effects. For example, we can observe how LOL players evaluate people who play other games such as DOTA (notice that DOTA and LOL players often tend to exhibit contempt for each other).

One limitation of the current study is that we only transformed the shape of the stimuli faces to manipulate the sexual dimorphic features, but shape is not the sole predictor of 
perceived sexually dimorphic facial features (Carrito \& Semin, 2019). Additionally, manipulation methods and the definition of sexual dimorphic features may differ across studies (Rennels et al., 2008; Scott et al., 2010; DeBruine et al., 2010; Kleisner et al., 2021; Mitteroecker et al., 2015). Therefore, the current results should be interpreted carefully, as they are based strictly on shape-manipulated sexually dimorphic facial features. Future studies may consider using other methods of facial manipulation and exploring other facial information, such as facial coloration and other features.

\section{Conclusions}

To sum up, the present study found that gaming skills as social knowledge can affect players' perception of facial attractiveness. However, how gaming skill interacts with sexual dimorphism features - for example, whether players' group identity also regulates the sexual dimorphism effect in facial evaluations - requires further investigation.

\section{Appendix}

\section{Table 3}

Table 3 Results of the ANOVA that only includes fixed effects (no random effects), using Face Gender (male, female) and Sexualized Characteristics (masculinized, feminized) as within-subjects factors, and Gaming Skill (high, low) and Play Group (game player, nonplayer) as between-subjects factors

\begin{tabular}{llllll}
\hline Factor & $F$ & & $d f$ & $p$ & $\eta_{p}^{2}$ \\
\hline Face Gender & $\mathbf{4 0 . 1 5}$ & $\mathbf{1}$ & $\mathbf{3 1 0}$ & $<\mathbf{0 . 0 0 1}$ & $\mathbf{0 . 1 1 5}$ \\
Sexualized Characteristics & 0.64 & 1 & 310 & 0.219 & 0.002 \\
Gaming Skill & $\mathbf{1 8 . 2 2}$ & $\mathbf{1}$ & $\mathbf{3 1 0}$ & $<\mathbf{0 . 0 0 1}$ & $\mathbf{0 . 0 5 5}$ \\
Player Group & 0.10 & 1 & 310 & 0.741 & $<0.001$ \\
FG $\times$ SC & $\mathbf{1 2 . 5 3}$ & $\mathbf{1}$ & $\mathbf{3 1 0}$ & $<\mathbf{0 . 0 0 1}$ & $\mathbf{0 . 0 3 8}$ \\
FG $\times$ GS & 0.35 & 1 & 310 & 0.553 & 0.001 \\
SC $\times$ GS & 0.61 & 1 & 310 & 0.433 & 0.002 \\
FG $\times$ PG & $\mathbf{6 . 7 8}$ & $\mathbf{1}$ & $\mathbf{3 1 0}$ & $\mathbf{0 . 0 0 9}$ & $\mathbf{0 . 0 2 1}$ \\
SC $\times$ PG & 0.95 & 1 & 310 & 0.330 & 0.003 \\
GS $\times$ PG & $\mathbf{4 . 1 3}$ & $\mathbf{1}$ & $\mathbf{3 1 0}$ & $\mathbf{0 . 0 4 2}$ & $\mathbf{0 . 0 1 3}$ \\
FG $\times$ SC $\times$ GS & 0.14 & 1 & 310 & 0.703 & $<0.001$ \\
FG $\times$ SC $\times$ PG & 2.04 & 1 & 310 & 0.153 & 0.006 \\
FG $\times$ GS $\times$ PG & 0.34 & 1 & 310 & 0.558 & 0.001 \\
SC $\times$ GS $\times$ PG & 0.61 & 1 & 310 & 0.441 & 0.003 \\
FG $\times$ SC $\times$ GS $\times$ PG & 0.59 & 1 & 310 & 0.442 & 0.002 \\
\hline
\end{tabular}

$\mathrm{FG}=$ Face Gender; SC = Sexualized Characteristics; GS = Gaming Skill; $\mathrm{PG}=$ Play Group;

Two slight difference between the results of the fixed effect ANOVA and the most parsimonious random-effects model were: (1) main effect Face Gender was not significant in the random-effects model. (2) the three interaction between FG, SC and PG was significant in the random-effects model. Bold means p-value is less that 0.05 .
Funding This research is supported by the National Natural Science Foundation of China (Grant No. 32100852 and 72002123).

Data availability The data that support the results of the present study are openly available in Open Science Framework at: https://osf.io/ b6ukf/?view_only=5155d45b0a1f482a9ab34f99e16edda0.

Code availability The $\mathrm{R}$ code that supports the results of the present study are openly available in Open Science Framework at: https://osf. io/b6ukf/?view_only=5155d45b0a1f482a9ab34f99e16edda0.

\section{Declarations}

Conflicts of interest/Competing interests The authors declare that the research was conducted in the absence of any commercial or financial relationships that could be construed as a potential conflict of interest.

Ethics statement of the survey The approval of ethical standards for the present study was given by the Ethics Committee of authors' institution. All participants provided informed consent by checking a box to confirm they had fully understood the implications of participation and their right to withdraw at any point.

\section{References}

Bediou, B., Adams, D. M., Mayer, R. E., Tipton, E., Green, C. S., \& Bavelier, D. (2018). Meta-Analysis of Action Video Game Impact on Perceptual, Attentional, and Cognitive Skills. 144(1), 77-110.

Bird, B. M., Welling, L. L., Ortiz, T. L., Moreau, B. J., Hansen, S., Emond, M., et al. (2016). Effects of exogenous testosterone and mating context on men's preferences for female facial femininity. Hormones and Behavior, 85, 76-85.

Boot, W. R., Kramer, A. F., Simons, D. J., Fabiani, M., \& Gratton, G. (2008). The effects of video game playing on attention, memory, and executive control. Acta Psychologica, 129, 387-398.

Brewer, M. B. (1988). A dual process model of impression formation. In T. K. Srull, \& R. S. WyerJr. (Eds.). Advances in social cognition. A dual process model of impression formation (Vol. 1, pp. 1-36). Lawrence Erlbaum Associates, Inc.

Burriss, R. P., Marcinkowska, U. M., \& Lyons, M. T. (2014). Gaze properties of women judging the attractiveness of masculine and feminine male faces. Evolutionary Psychology, 12(1), $19-35$.

Carrito, M. L., \& Semin, G. R. (2019). When we don't know what we know - Sex and skin color. Cognition, 191(June), 103972.

Chopin, A., Bediou, B., \& Bavelier, D. (2019). Altering perception: the case of action video gaming. Current Opinion in Psychology, 29, 168-173.

DeBruine, L. M., Jones, B. C., Smith, F. G., \& Little, A. C. (2010) Are attractive men's faces masculine or feminine? The importance of controlling confounds in face stimuli. Journal of Experimental Psychology Human Perception and Performance, 36(3), 751-758.

Dobrowolski, P., Hanusz, K., Sobczyk, B., Skorko, M., \& Wiatrow, A. (2015). Cognitive enhancement in video game players: The role of video game genre. Computers in Human Behavior, 44, 59-63.

Dunn, M. J., \& Searle, R. (2010). Effect of manipulated prestige-car ownership on both sex attractiveness ratings. British Journal of Psychology, 101, 69-80.

Dunn, M. J., \& Hill, A. (2014). Manipulated luxury-apartment ownership enhances opposite-sex attraction in females but not males. Journal of Evolution Psychology, 12, 1-17. 
Everett, J. A. C., Faber, N. S., \& Crockett, M. (2015). Preferences and beliefs in ingroup favoritism. Frontiers in Behavioral Neuroscience, 9(FEB), 1-21.

Faul, F., Erdfelder, E., Lang, A. G., \& Buchner, A. (2007). G*Power 3: A flexible statistical power analysis program for the social, behavioral, and biomedical sciences. Behavior Research Methods, 39, 175-191.

Glick, P., Larsen, S., Johnson, C., \& Branstiter, H. (2005). Evaluations of sexy women in low-and high-status jobs. Psychology of Women Quarterly, 29, 389-395.

Green, C. S., \& Bavelier, D. (2003). Action video game modifies visual selective attention. Nature, 423, 534-537.

Green, C. S., \& Bavelier, D. (2006). Effect of action video games on the spatial distribution of visuospatial attention. Journal of Experimental Psychology: Human Perception and Performance, $1465-1468$.

Li, X., Huang, L., Li, B., Wang, H., \& Han, C. (2020). Time for a true display of skill: Top players in League of Legends have better executive control. Acta Psychologica, 204(January), 103007.

Han, S., Liu, S., Li, Y., Li, W., Wang, X., Gan, Y., \& Zhang, L. (2020). Why do you attract me but not others? Retrieval of person knowledge and its generalization bring diverse judgments of facial attractiveness. Social Neuroscience, OO(00), 505-515.

Han, C., Li, X., Chen, X., Lei, X., Liao, C., Zhang, L., \& Morrison, E. R. (2021). The autumn years: age differences in preferences for sexually dimorphic faces. Archives of Sexual Behavior, $0123456789,5$.

Howlett, N., Pine, K. J., Cahill, N., Orakçı־ glu, I., \& Fletcher, B. C. (2015). Unbuttoned: the interaction between provocativeness of female work attire and occupational status. Sex Roles, 72, 105-116.

Heilman, M. E., Wallen, A. S., Fuchs, D., \& Tamkins, M. M. (2004). Penalties for success: reactions to women who succeed at male gender-typed tasks. Journal of Applied Psychology, 89, 416-427.

Holm, S. (1979). A simple sequentially rejective multiple test procedure. Scandinavian Journal of Statistics, 5(2), 65-70.

Karakus, T., Inal, Y., \& Cagiltay, K. (2008). A descriptive study of Turkish high school students' game-playing characteristics and their considerations concerning the effects of games. Computers in Human Behavior, 24(6), 2520-2529.

Kleisner, K., Tureček, P., Roberts, S. C., Havlíček, J., Valentova, J. V., Akoko, R. M. \& Leogómez, J. D et al. (2021). How and why patterns of sexual dimorphism in human faces vary across the world. Science Reports, 11, 5978. https://doi.org/10.1038/s41598-021-85402-3.

Kowert, R., \& Oldmeadow, J. A. (2013). A)Social reputation: Exploring the relationship between online video game involvement and social competence. Computers in Human Behavior, 29(4), $1872-1878$.

Kuznetsova, A., Brockhoff, P. B., \& Christensen, R. H. B. (2017). lmerTest Package: Tests in Linear Mixed Effects Models. Journal of Statistical Software, 82(13), 1-26. https://doi.org/10.18637/ jss.v082.i13.

Little, A. C., Burt, D. M., \& Perrett, D. I. (2006). What is good is beautiful: Face preference reflects desired personality. Personality and Individual Differences, 41(6), 1107-1118.

Luke, S. G. (2017). Evaluating significance in linear mixed-effects models in R. Behavior Research Methods, 49(4), 1494-1502.

Mattan, B. D., Kubota, J. T., \& Cloutier, K. J. (2017). How social status shapes person perception and evaluation: a social neuroscience perspective. Perspectives on Psychological Science, 3, 468-507.

Mitteroecker, P., Windhager, S., Møller, G. B., \& Schaefer, K. (2015). The morphometrics of "masculinity" in human faces. PLOS ONE, 10(2), e0118374.

Mullen, B., Brown, R., \& Smith, C. (1992). Ingroup bias as a function of salience, relevance, and status: An integration. European Journal of Social Psychology, 22(2), 103-122.
Nuyens, F. M., Kuss, D. J., Lopez-Fernandez, O., \& Griffiths, M. D. (2019). The empirical analysis of non-problematic video gaming and cognitive skills: a systematic review. International Journal of Mental Health and Addiction, 17(2), 389-414.

Oh, D. W., Shafir, E., \& Todorov, A. (2020). Economic status cues from clothes affect perceived competence from faces. Nature Human Behaviour, 4(3), 287-293.

Olivola, C. Y., Funk, F., \& Todorov, A. (2014). Social attributions from faces bias human choices. Trends in Cognitive Sciences, 18(11), 566-570.

Perrett, D. I., Lee, K. J., Penton-Voak, I. S., Rowland, D. R., \& Akamatsu, S. (1998). Effects of sexual dimorphism on facial attractiveness. Nature, 394(6696), 884-887.

Quinn, K. A., \& Macrae, C. N. (2011). The face and person perception: Insights from social cognition. British Journal of Psychology, 102(4), 849-867.

R Core Team. (2019). R: a language and environment for statistical computing. R Foundation for Statistical Computing.

Rennels, J. L., Bronstad, P. M., \& Langlois, J. H. (2008). Are attractive men's faces masculine or feminine? The importance of type of facial stimuli. Journal of Experimental Psychology Human Perception and Performance, 34(4), 884-893.

Rhodes, G. (2006). The evolutionary psychology of facial beauty. Annual Review of Psychology, 57(1), 199-226.

Ritchie, K. L., Palermo, R., \& Rhodes, G. (2017). Forming impressions of facial attractiveness is mandatory. Scientific Reports, 7Article Number(1), 469.

Scott, I. M. L., Pound, N., Stephen, I. D., Clark, A. P., \& Penton-Voak, I. S. (2010). Does masculinity matter? The contribution of masculine face shape to male attractiveness in humans. PLOS ONE, 5(10), e13585.

Scott, I., Swami, V., Josephson, S. C., \& Penton-Voak, I. S. (2008). Context-dependent preferences for facial dimorphism in a rural Malaysian population. Evolution and Human Behavior, 29(4), 289-296.

Stephen, I., \& Luoto, S. (2021). Physical cues of partner quality. In L. Lisa \& T. Shackelford (Eds.), The Oxford Handbook of Evolutionary Psychology and Behavioral Endocrinology (pp. 421-452). Rochester, MI: USA. Oxford University Press.

Stoet, G. (2010). PsyToolkit: A software package for programming psychological experiments using Linux. Behavior Research Methods, 42(4), 1096-1104.

Stoet, G. (2017). PsyToolkit. Teaching of Psychology, 44(1), 24-31.

Sutherland, C. A. M., Young, A. W., \& Rhodes, G. (2016). Facial first impressions from another angle: How social judge- ments are influenced by changeable and invariant facial properties. British Journal of Psychology, 108(2), 397-415.

Todorov, A., Olivola, C. Y., Dotsch, R., \& Mendesiedlecki, P. (2015). Social Attributions from Faces: Determinants, consequences, accuracy, and functional significance. Annual Review of Psychology, 66(1), 519-545.

Unsworth, N., Redick, T. S., McMillan, B. D., Hambrick, D. Z., Kane, M. J., \& Engle, R. W. (2015). Is playing video games related to cognitive abilities? Psychological Science, 26, 759774.

Vernon, R. J., Sutherland, C. A., Young, A. W., \& Hartley, T. (2014). Modeling first impressions from highly variable facial images. Proceedings of the National Academy of Sciences of the United States of America, 111(32), E3353-E3361.

Wang, X., Liu, S., Han, S., Gan, Y., Li, W., Xu, Q., \& Zhang, L. (2020). Roles of social knowledge and sexual dimorphism in the evaluation of facial attractiveness. Journal of Experimental Social Psychology, 88(818), 103963.

Welling, L. L., Jones, B. C., DeBruine, L. M., Smith, F. G., Feinberg, D. R., Little, A. C., \& Al- Dujaili, E. A. (2008). Men report stronger attraction to femininity in women's faces when their 
testosterone levels are high. Hormones and Behavior, 54(5), 703-708.

Zebrowitz, L. A., \& Franklin, R. G. (2014). The attractiveness halo effect and the baby face stereotype in older and younger adults: Similarities, own-age accentuation, and older adult positivity effects. Experimental Aging Research, 40(3), 375-393.
Publisher's Note Springer Nature remains neutral with regard to jurisdictional claims in published maps and institutional affiliations. 